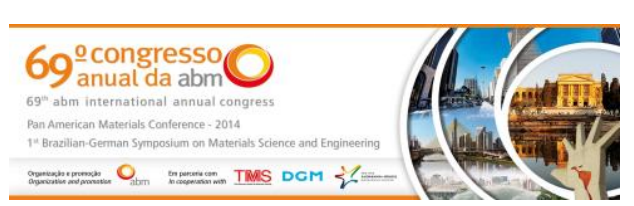

Tema: Iniciação Científico-tecnológica

\title{
SÍNTESE E CARACTERIZAÇÃO DE ALUMINA DOPADA COM ESTRÔNCIO VIA MOAGEM ÚMIDA*
}

\author{
Ivy Frazão ${ }^{1}$ \\ Gilberto José Pereira²
}

\section{Resumo}

O presente projeto teve como objetivo a síntese com alta homogeneidade química, utilizando a reações no estado sólido através de moagem úmida, envolvendo alumina em sua fase mais estável (corundum) dopada com íons de estrôncio. Foram utilizados como fonte de $\mathrm{Sr}^{2+}$ tanto óxidos quanto nitratos e carbonatos e variou-se também o meio de moagem (aquoso e alcoólico), a temperatura de calcinação e a concentração de dopante. Para a caracterização do material foram realizadas difrações de raios-x e espectrometria por fluorescência. O potencial catalítico da alumina dopada com $\mathrm{Sr}^{2+}$ é conhecido para reações de transesterificação, e os estudos deste sistema que são encontrados na literatura apontam para a formação de compostos intermediários, porém utilizando diferentes rotas de síntese. Os resultados preliminares indicam que por moagem úmida não há a formação de compostos intermediários.

Palavras-chave: Alumina; Estrôncio; Síntese por mistura de óxidos.

\section{SYNTHESIS AND CHARACTERIZATION OF ALUMINA DOPED WITH STRONTIUM BY WET MILLING}

\section{Abstract}

This project aimed to the synthesis with high chemical homogeneity, adopting the reactions in the solid state through wet milling, which comprises alumina in its most stable phase (corundum) doped with strontium ions. Oxides, carbonates and nitrates were used as source of $\mathrm{Sr}^{2+}$. In addition, other variations include the milling process (both aqueous and alcoholic), the calcining temperature and dopant concentration. In order to characterize the material, XRD and fluorescence spectrometry were used. The catalytic potential of alumina doped with $\mathrm{Sr}^{2+}$ is known to transesterification reactions, and studies of this system are found in the literature pointing to the formation of intermediate compounds, although employing different synthesis routes. Preliminary results indicate that for the wet milling process there is no formation of intermediate compounds.

Keywords: Alumina; Strontium; Synthesis by mixing oxides.

1 Graduanda em Engenharia de Materiais, Centro Universitário da FEl, São Bernardo do Campo, SP, Brasil.

2 Engenheiro de Materiais, Dr., Departamento de Engenharia de Materiais, Centro Universitário da FEl, São Bernardo do Campo, SP, Brasil.

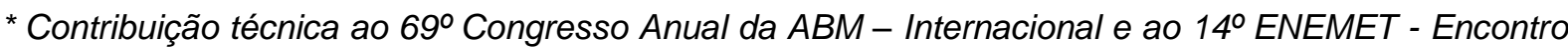
Nacional de Estudantes de Engenharia Metalúrgica, de Materiais e de Minas, 21 a 25 de julho de 2014, São Paulo, SP, Brasil.
} 




\section{INTRODUÇÃO}

O óxido de alumínio ou alumina, como é comumente conhecido, é um material cerâmico de interessantes propriedades e variadas aplicações. Sabe-se que as diferentes propriedades da alumina estão relacionadas com as diversas fases cristalinas em que ela se apresenta. A natureza da alumina depende consideravelmente de fatores como a sua microestrutura, forma cristalina e impurezas presentes, podendo apresentar algumas fases cristalográficas como alfa, gama, delta e teta.[1]

A estrutura $\alpha-\mathrm{Al}_{2} \mathrm{O}_{3}$, também chamada de corundum, pode ser obtida através do processo Bayer e é a fase mais estável da alumina em temperatura ambiente. Apesar disso, ela não é a única fase presente nessas condições. Também é possível encontrar algumas fases metaestáveis da alumina. Essas fases se estabilizam devido a sua baixa energia de superfície e, dentre elas, a mais estudada é a $\gamma-\mathrm{Al}_{2} \mathrm{O}_{3}$. [2]

A importância da $\gamma-\mathrm{Al}_{2} \mathrm{O}_{3}$ deve-se ao fato dessa estrutura possuir uma alta área de superfície específica (o que the confere boas propriedades catalíticas), diferentemente da $\alpha-\mathrm{Al}_{2} \mathrm{O}_{3}$. $\mathrm{A}$ transição $\gamma-\mathrm{Al}_{2} \mathrm{O}_{3}$ para $\alpha-\mathrm{Al}_{2} \mathrm{O}_{3}$ vem sendo amplamente estudada, devido a essa variação nas propriedades catalíticas já mencionadas, visando o maior controle da sinterização e da microestrutura da alumina formada.

Alguns pesquisadores, como Wakao [3], Machida [4], Okada [5] e Yoldas [6], estudaram a obtenção de óxido de alumínio através de diferentes rotas de síntese que não o método Bayer, e relataram a influência da adição de cátions na temperatura de transição da alumina gama para a alfa. Cátions como $\mathrm{Fe}^{3+}$ e $\mathrm{Ti}^{4+}$, são conhecidos por acelerar a transição de fase, enquanto $\mathrm{Ba}^{+}, \mathrm{La}^{+3} \mathrm{e} \mathrm{Si}^{+4}$, são conhecidos por retardá-la. Nos estudos de Okada et al [5] foram analisadas as influências de diversos outros íons, entre eles o $\mathrm{Sr}^{+2}$, e concluiu-se que os elementos da família II $A$, tendem a retardar a transição, aumentando portanto, a eficiência da alumina como catalisador. Além disso, analisando os compostos intermediários formados, notou-se que a estrutura cristalina dos mesmos, não afeta a transição e sim a diferença de raio atômico entre o cátion adicionado e $\circ \mathrm{Al}^{+3}$ presente na estrutura da alumina. [5]

Existem diferentes compostos cristalinos no sistema $\mathrm{Al}_{2} \mathrm{O}_{3}-\mathrm{SrO}$, sendo os mais conhecidos $\mathrm{Sr}_{3} \mathrm{Al}_{2} \mathrm{O}_{6}, \mathrm{SrAl}_{2} \mathrm{O}_{4}, \mathrm{Sr}_{4} \mathrm{Al}_{14} \mathrm{O}_{25}, \mathrm{SrAl}_{4} \mathrm{O}_{7}$ e $\mathrm{SrAl}_{12} \mathrm{O}_{19}$. [7] A adição de quantidades estequiométricas de estrôncio a partir de sais, como nitratos, durante a síntese de alumina pelo método dos precursores poliméricos e via ácido cítrico, têm indicado a formação de compostos $\mathrm{AlSr}_{4} \mathrm{O}_{7}$ ou $\mathrm{Al}_{2} \mathrm{Sr}_{2} \mathrm{O}_{4}$, dependendo das condições de síntese [8].

Vishista et al [9] analisou as propriedades de gama alumina com a introdução de cátions de estrôncio, durante a preparação dos pós pela rota de síntese sol-gel. Os resultados apontaram para uma alteração na fase cristalina, que não a evolução para alfa alumina, e sim para uma fase do tipo espinélio.

De semelhante modo, Okada et al [5] também observou a formação de uma fase espinélio, e de uma fase metaestável $\left(\mathrm{SrAl}_{4} \mathrm{O}_{7}\right)$, além de constatar que a transição de gama para alfa alumina ocorre em temperaturas mais elevadas. Contudo, Pereira et al [10] ao sintetizar amostras pela rota dos precursores poliméricos não observou a presença de fases secundárias, desde que utilizando pequenas quantidades de aditivos e com baixas temperaturas de calcinação. Foi observado, assim como Okada, que a transição de fases gama alfa ocorreu em temperaturas mais altas,

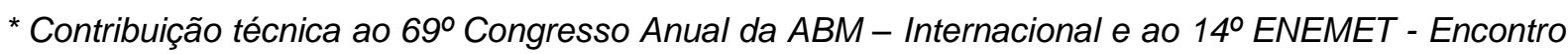
Nacional de Estudantes de Engenharia Metalúrgica, de Materiais e de Minas, 21 a 25 de julho de 2014, São Paulo, SP, Brasil.
} 


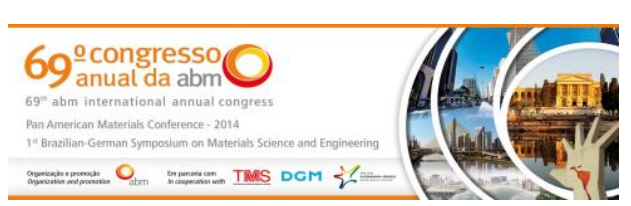

independente da rota de síntese empregada, mostrando que a interação e as consequências da introdução de estrôncio nos compostos de alumina produz um material com variadas propriedades.

O presente trabalho tem por objetivo produzir um material potencialmente catalítico, a base de alumina dopada com íons de estrôncio, sintetizada através da mistura mecânica da alumina com diferentes precursores de estrôncio, que após o tratamento térmico, promovem reações difusionais no estado sólido em $\alpha-\mathrm{Al}_{2} \mathrm{O}_{3}$ causando a formação de óxido de estrôncio na superfície da alumina, ou ainda promova a formação de compostos intermediários. O ineditismo deste tema jaz no fato de que já existem outros estudos sobre esse mesmo sistema, porém utilizando rotas de síntese diferentes.

O processo de reação no estado sólido deu-se através da calcinação. Esse processo é utilizado para a obtenção de pós mais complexos, a partir de pós mais simples como nitratos, óxidos, carbonatos, sulfatos e acetatos. [11] Por ser um processo simples e de baixo custo, foi o escolhido para a realização desse trabalho. Os pós produzidos foram analisados quanto a sua composição química e de fases para assegurar sua eficiência e reprodutibilidade do processo.

\section{MATERIAIS E MÉTODOS}

\subsection{Síntese de Amostras}

Para realizar a síntese química dos pós de alumina contendo diferentes quantidades de estrôncio, os materiais necessários são: moinho de bolas, elementos densos de alumina, frascos de polietileno, Alumina CT3000SG (Almatis), álcool etílico (Dinâmica), água bidestilada e deionizada a $5 \mu \mathrm{S} / \mathrm{cm}$, além de carbonato de estrôncio $\left(\mathrm{SrCO}_{3}\right)$, nitrato de estrôncio $\mathrm{Sr}\left(\mathrm{NO}_{3}\right)_{2}$ e óxido de estrôncio (todos Aldrich). O nitrato de estrôncio utilizado estava diluído em água, para facilitar a estocagem e garantir a estequiometria.

Amostras contendo 5 gramas de alumina foram dopadas com $10 \%$ e $30 \%$ em mol de óxido, carbonato e nitrato de estrôncio, e submetidas a 12 horas de moagem, tanto em meio alcoólico quanto em meio aquoso. Foram utilizados $20 \mathrm{ml}$ de água/álcool em cada amostra. Também foram feitas amostras de alumina sem nenhuma dopagem em meio aquoso e alcoólico, para serem utilizadas como referência.

Foi observado o comportamento exotérmico nas amostras dopadas com óxido de estrôncio em meio aquoso. Isso ocorreu no momento de adição da água.

As amostras foram filtradas utilizando uma bomba de vácuo, kitassato, funil de Hall e papel de filtro.

$\mathrm{Na}$ sequência, foram colocadas para secar em uma estufa à $120^{\circ} \mathrm{C}$ por um período de 6 horas. A calcinação foi feita com uma rampa de aquecimento de $10^{\circ} \mathrm{C}$ por minuto, à $600^{\circ} \mathrm{C}$ por 6 horas usando cadinhos de porcelana. Após preparadas, as amostras foram armazenadas em frascos de polietileno.

Para analisar melhor o efeito de cada etapa do processo, também foram preparadas amostras não calcinadas.

\subsection{Difração de Raios X}

Os ensaios de difração de raios $X$ são imprescindíveis para um estudo das fases presentes nas amostras estudadas após a síntese e após as etapas de calcinação. $O$ equipamento de difração de raios $X$ utilizado é um Shimadzu XRD-7000, com a

\footnotetext{
* Contribuição técnica ao $69^{\circ}$ Congresso Anual da ABM - Internacional e ao 14ํㅡㄹ ENEMET - Encontro Nacional de Estudantes de Engenharia Metalúrgica, de Materiais e de Minas, 21 a 25 de julho de 2014, São Paulo, SP, Brasil.
} 


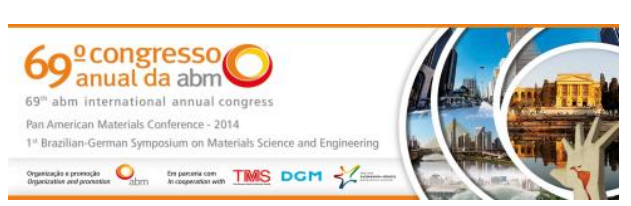

radiação $\mathrm{K} \alpha-\mathrm{Cu}$, cujo comprimento de onda é 1,54056 $\AA$, utilizando o intervalo padrão $2 \theta$ de $20^{\circ}$ a $80^{\circ}$ em passo de $0,04^{\circ}$, com tempo de exposição de 2,0 segundos, disponível no Centro Universitário da FEI Campus São Bernardo do Campo.

Para a realização dos ensaios de difração de raios $x$, as amostras foram cominuídas utilizando um almofariz e um pistilo e colocadas no porta amostra, de modo a preencher sua cavidade, sempre mantendo a superfície o mais plana possível.

Os espectros obtidos foram comparados com as cartas da alumina, do óxido, do nitrato, do carbonato de estrôncio e de diversos compostos cristalinos no sistema $\mathrm{Al}_{2} \mathrm{O}_{3}-\mathrm{SrO}$, todas retiradas do banco de dados DDView 2008 - International Center of Difraction Data.

\subsection{Análise Química}

O ensaio de espectrometria por fluorescência de raios $X$ Axio Advanced foi realizado em todas as amostras calcinadas pelo Laboratório de Caracterização Tecnológica da Escola Politécnica da Universidade de São Paulo, utilizando um equipamento marca PANanytical.

Utilizou-se o método de análise sem padrões de elementos químicos detectados, de flúor à urânio.

\section{RESULTADOS E DISCUSSÃO}

\subsection{Análise das Amostras de Referência}

A comparação entre a alumina recebida e as amostras de referência (alumina moída em meio aquoso em meio alcoólico) foi feita através do difratograma mostrado na figura 1.

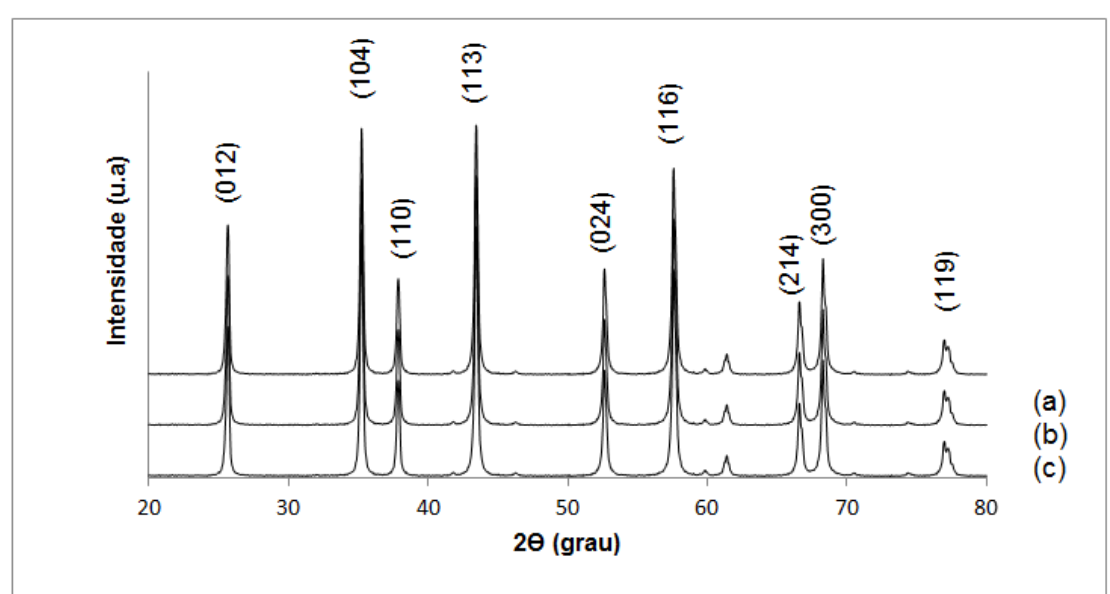

Figura 1 - Difratogramas da alumina em diferentes condições: (a) $\mathrm{Al}_{2} \mathrm{O}_{3}$ moída em álcool; (b) $\mathrm{Al}_{2} \mathrm{O}_{3}$ moída em água; (c) $\mathrm{Al}_{2} \mathrm{O}_{3}$ como recebida.

É possível observar que não há grande variação nos difratogramas obtidos. Não houve, portanto, alteração estrutural na alumina causada pelas etapas de moagem, filtração e calcinação. As fases presentes são as mesmas para todas as aluminas.

\footnotetext{
* Contribuição técnica ao $69^{\circ}$ Congresso Anual da ABM - Internacional e ao 14ํㅡㄹ ENEMET - Encontro Nacional de Estudantes de Engenharia Metalúrgica, de Materiais e de Minas, 21 a 25 de julho de 2014, São Paulo, SP, Brasil.
} 


\subsection{Difratogramas}

Os difratogramas obtidos para as amostras dopadas são analisados na sequência de precursores. Primeiro o Carbonato, depois o nitrato e por último o óxido, em diferentes concentrações.

\subsubsection{Carbonato de Estrôncio como precursor de Sr${ }^{2+}$}

Observou-se que nas amostras dopadas com carbonato os picos presentes coincidiram com os da alumina e os do carbonato puros. Não houve, portanto, o deslocamento de nenhum pico, nem a formação de nenhuma nova fase cristalina, como pode ser visto nas figuras 2 e 3 .

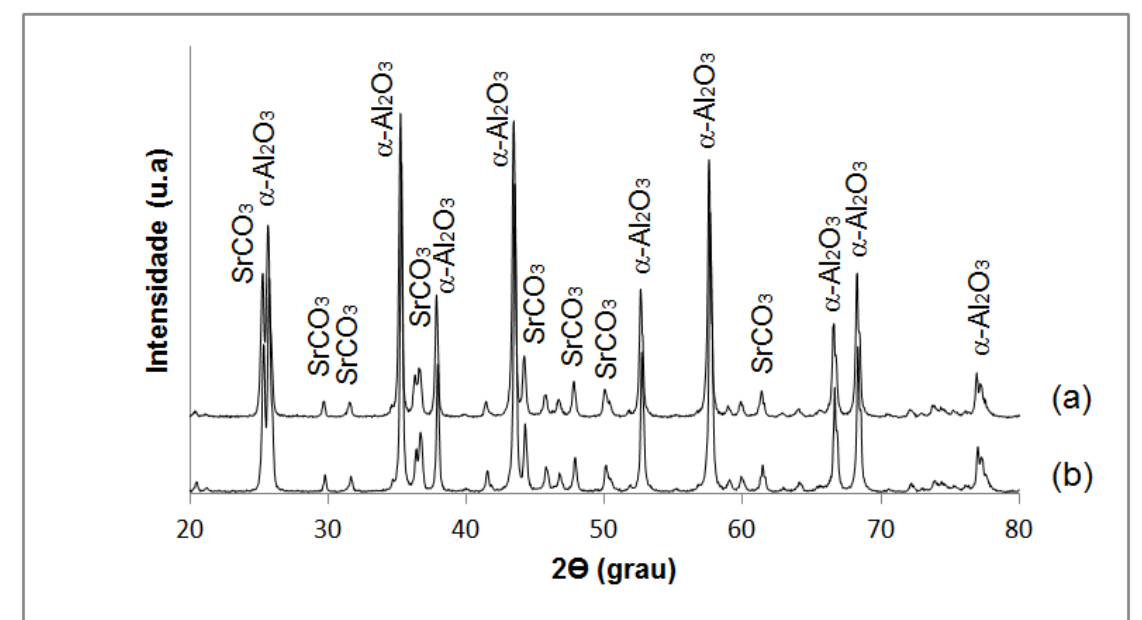

Figura 2 - Difratograma da amostra de alumina calcinada dopada com $10 \% \mathrm{SrCO}_{3}$ em meio aquoso (a) e em meio alcoólico (b).

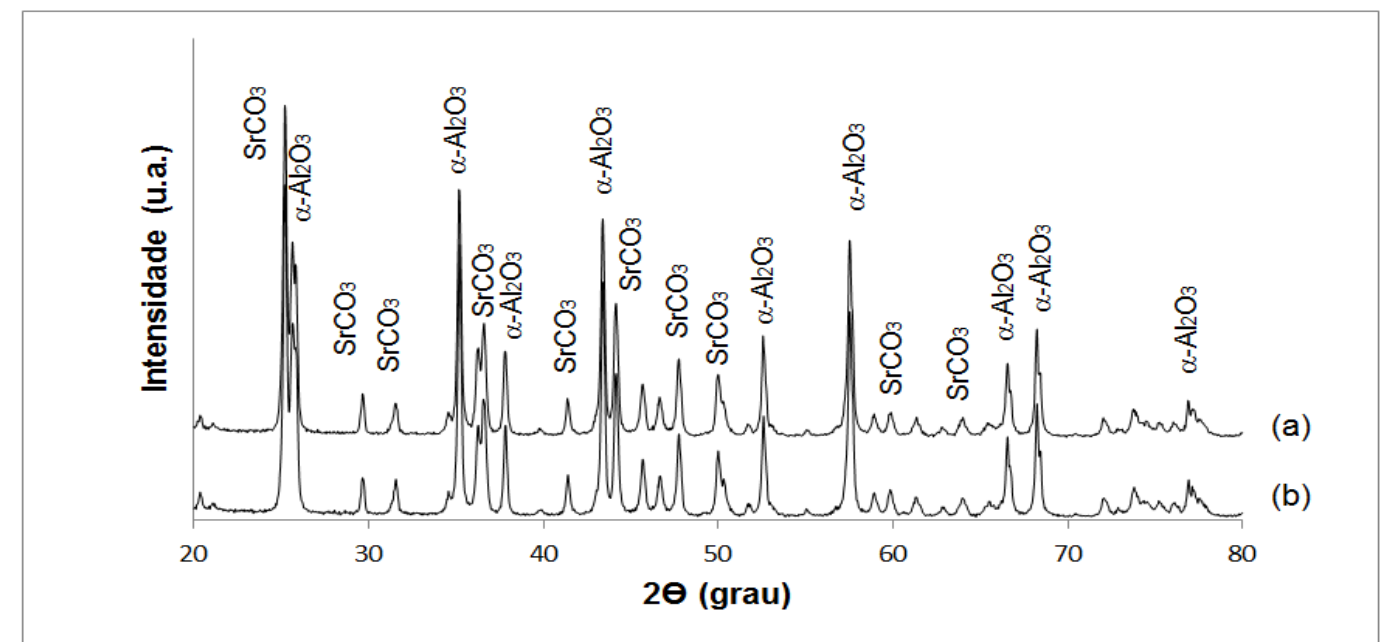

Figura 3 - Difratograma da amostra de alumina calcinada dopada com $30 \% \mathrm{SrCO}_{3}$ em meio aquoso (a) e em meio alcoólico (b).

A decomposição do carbonato de estrôncio não ocorreu nas condições empregadas e a presença do carbonato pôde ser percebida independente do meio líquido de moagem.

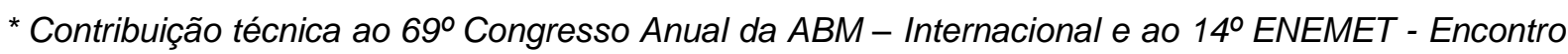
Nacional de Estudantes de Engenharia Metalúrgica, de Materiais e de Minas, 21 a 25 de julho de 2014, São Paulo, SP, Brasil.
} 


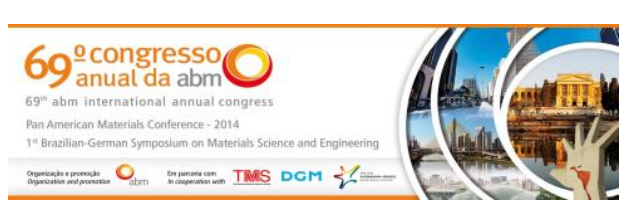

\subsubsection{Nitrato de Estrôncio como precursor de $\mathrm{Sr}^{2+}$}

Nas amostras dopadas com nitrato em meio aquoso foi observado um difratograma muito próximo ao da alumina moída em água sem dopante, como pode ser visto nas figuras 4 e 5 .



Figura 4 - Difratograma da amostra de alumina dopada calcinada com $30 \% \mathrm{Sr}\left(\mathrm{NO}_{3}\right)_{2}$ em meio aquoso (a) e em meio alcoólico (b) e com $10 \% \operatorname{Sr}\left(\mathrm{NO}_{3}\right)_{2}$ em meio alcoólico (c).

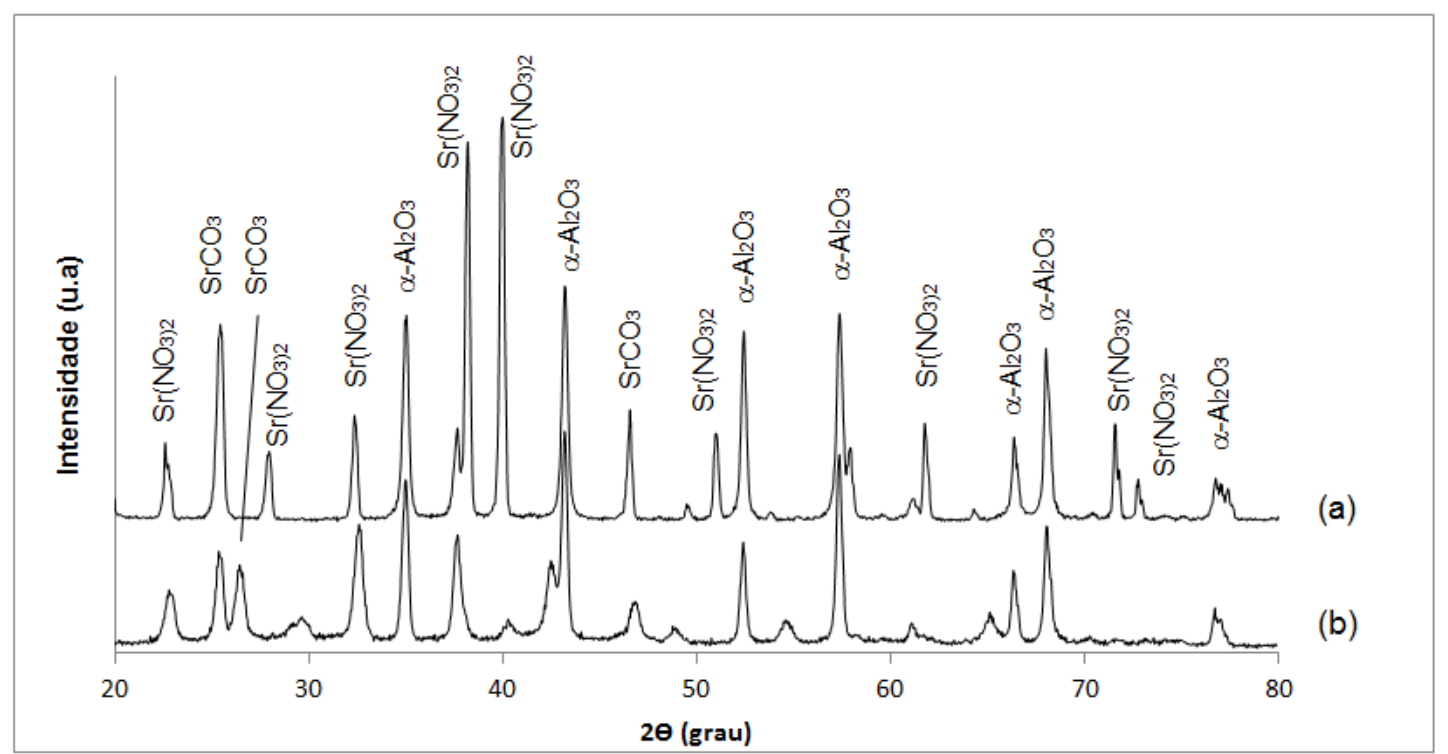

Figura 5 - Difratograma da amostra de alumina dopada com 10\% $\mathrm{Sr}\left(\mathrm{NO}_{3}\right)_{2}$ em meio alcoólico sem calcinar (b) e calcinada (b).

Devido a alta solubilidade do nitrato em meio aquoso $(80 \mathrm{~g} / 100 \mathrm{ml}$ a $180 \mathrm{C})$ [12] na etapa de filtração ele é eliminado juntamente com a água resultando em um difratograma muito simular ao da a-alumina. Isso pôde ser observado mesmo nas amostras preparadas em álcool, visto que o nitrato de estrôncio utilizado já se encontrava diluído em água.

$\mathrm{Na}$ amostra de alumina não calcinada dopada com $10 \% \mathrm{Sr}\left(\mathrm{NO}_{3}\right)_{2}$ em meio alcoólico foi observada a presença de picos referentes ao nitrato de estrôncio, o que é esperado visto que este é o precursor. Nas demais análises o comportamento das amostras não calcinadas foi o mesmo das respectivas amostras calcinadas.

* Contribuição técnica ao 69 Congresso Anual da ABM - Internacional e ao 14ํㅡㄹ ENEMET - Encontro Nacional de Estudantes de Engenharia Metalúrgica, de Materiais e de Minas, 21 a 25 de julho de 2014, São Paulo, SP, Brasil. 


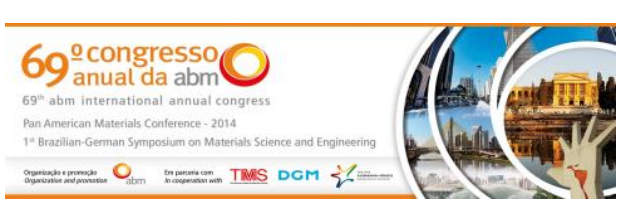

superfície é frequente e, além disso, a decomposição de hidróxidos durante tratamentos térmicos resulta na formação de óxidos.


Figura 6 - Comparativo entre o difratograma do hidróxido de estrôncio e o obtido experimentalmente.

Ao analisar os difratogramas das amostras contendo óxido de estrôncio (figuras 7), observa-se que, assim como algumas amostras dopadas com nitrato, houve a formação de carbonato. Além disso, estão presentes picos referentes à alumina, ao óxido e a hidróxido de estrôncio.

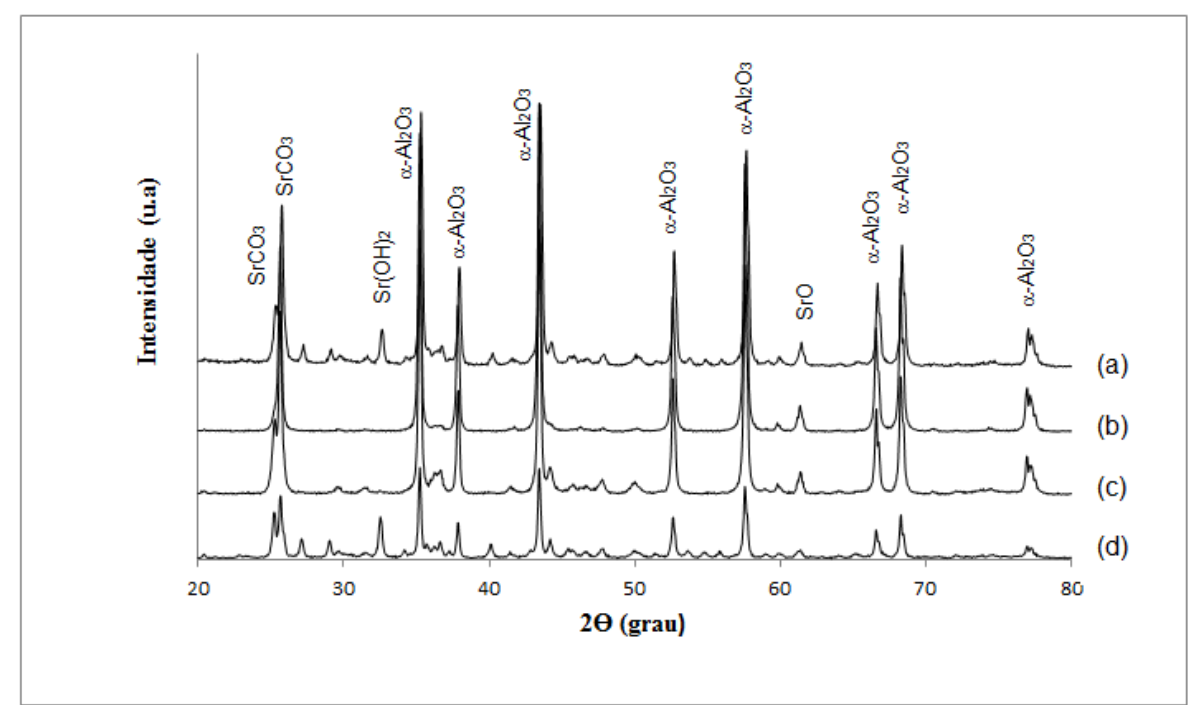

Figura 7 - Amostras calcinadas dopadas com: (a) 30\%SrO em meio alcoólico (b) 10\%SrO em meio aquoso (c) $10 \% \mathrm{SrO}$ em meio alcoólico (d) $30 \% \mathrm{SrO}$ em meio aquoso.

Quanto a exotermia observada nas amostras preparadas a partir de óxido de estrôncio em água, sabe-se que a água destilada e deionizada possui um valor de $\mathrm{pH}$ levemente ácido ( $\mathrm{pH}$ entre cinco e seis). Como o óxido de estrôncio tem seu ponto isoelétrico próximo de 12, com forte caráter iônico, este comportamento pode ser um indicativo de dissolução.

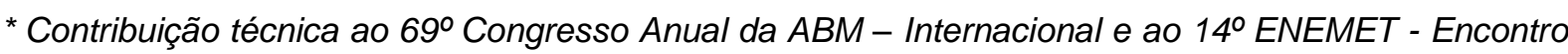
Nacional de Estudantes de Engenharia Metalúrgica, de Materiais e de Minas, 21 a 25 de julho de 2014, São Paulo, SP, Brasil.
} 


\subsection{Análises químicas}

A espectrometria de fluorescência forneceu o sinal de SrO presente em cada uma das amostras calcinadas, como pode ser visto nas figuras 8 e 9 .

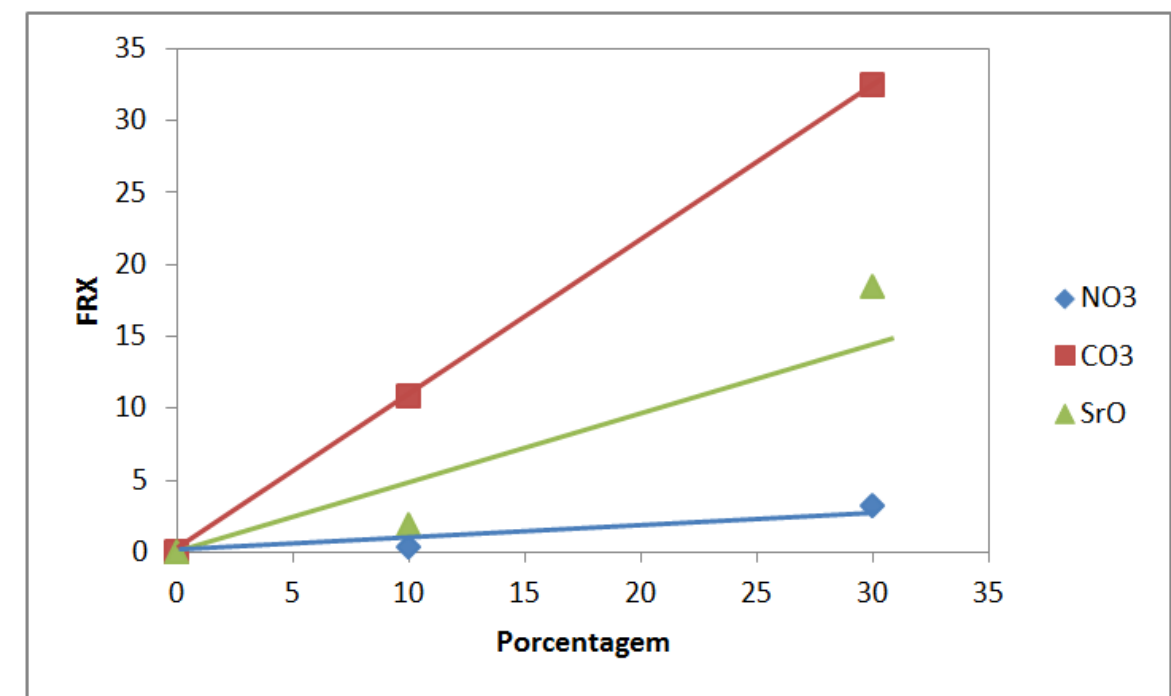

Figura 9 - Espectrometria de fluorescência para as amostras preparadas em meio aquoso.

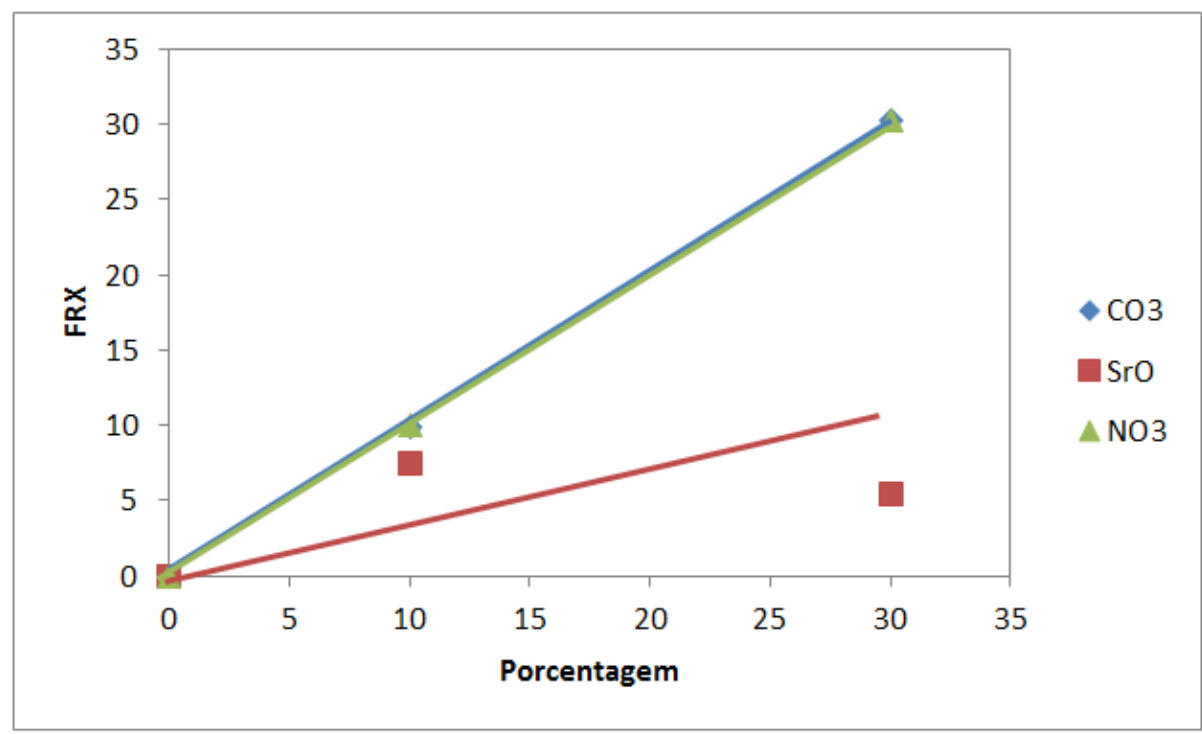

Figura 10 - Espectrometria de fluorescência para as amostras preparadas em meio alcoólico.

Os resultados obtidos comprovam a lixiviação do nitrato de estrôncio quando em meio aquoso, visto que os sinais de $\mathrm{SrO}$ obtidos foram todos inferiores a $4 \%$. Já em meio alcoólico não há sinal de lixiviação e as concentrações de SrO encontradas são muito similares as de nitrato de estrôncio utilizadas na preparação da amostra. $\mathrm{O}$ que é curioso, visto que o difratograma da amostra contendo $30 \% \mathrm{Sr}\left(\mathrm{NO}_{3}\right)_{2} \mathrm{em}$ meio alcoólico só apresenta picos referentes a a-alumina.

Para todas as amostras que utilizaram carbonato como precursor o sinal de SrO obtido foi próximo a concentração de carbonato utilizada. Já nas amostras que utilizaram óxido como precursor, o sinal de SrO obtido foi inferior à concentração de óxido utilizada na preparação das amostras.

\footnotetext{
* Contribuição técnica ao $69^{\circ}$ Congresso Anual da ABM - Internacional e ao 14ํㅡㄹ ENEMET - Encontro Nacional de Estudantes de Engenharia Metalúrgica, de Materiais e de Minas, 21 a 25 de julho de 2014, São Paulo, SP, Brasil.
} 




\section{CONCLUSÃo}

A introdução de cátions estrôncio na $\alpha-\mathrm{Al}_{2} \mathrm{O}_{3}$ foi feita através de nitratos, carbonatos e óxidos em diferentes concentrações. As amostras foram misturadas em moinho de bolas e calcinadas a $600^{\circ} \mathrm{C}$.

Observou-se que as amostras dopadas com carbonato não apresentaram a formação de nenhuma nova fase ou mesmo a formação de óxido de estrôncio cristalino. $\mathrm{O}$ óxido de estrôncio utilizado, devido às condições de armazenamento, era parcialmente composto por hidróxido de estrôncio que, ao reagir com o meio deu origem a carbonatos de estrôncio. Portanto, a análise do suposto óxido apresentou as fases cristalográficas presentes na $\alpha-\mathrm{Al}_{2} \mathrm{O}_{3}$, assim como fases do carbonato e do óxido de estrôncio.

O nitrato de estrôncio apresentou comportamento semelhante à alumina sem dopagem, devido a sua alta solubilidade em meio aquoso. Somente na amostra contendo $10 \% \mathrm{Sr}\left(\mathrm{NO}_{3}\right)_{2}$ em meio alcoólico foi notada a presença de uma ou mais novas fases, que não foram identificadas. Com a introdução de um percentual maior de nitrato de estrôncio o mesmo parece ter sido lixiviado pela água contida na solução aquosa segundo o difratograma obtido, porém, a análise química comprova a presença de estrôncio na amostra.

Estudos similares já haviam sido feitos por outros pesquisadores, porém através de diferentes métodos de síntese química. Esses estudos indicavam a presença de fases intermediárias no sistema $\mathrm{Al}_{2} \mathrm{O}_{3}-\mathrm{SrO}$ com características metaestáveis e/ou espinélio, que não foram identificadas nesse trabalho.

\section{Agradecimentos}

Gostaria de agradecer à empresa Almatis pela doação de alumina feita ao Centro Universitário da FEl. Essa alumina foi utilizada como matéria principal do meu estudo e tenho certeza que será de suma importância para diversos trabalhos realizados no Centro Universitário.

Quero ressaltar também que é muito importante para mim a publicação desse trabalho no ENEMET e agradeço à ABM por essa oportunidade.

Por fim gostaria de agradecer ao Centro Universitário da FEI por toda estrutura fornecida, que possibilitou tanto a síntese das amostras quanto a elaboração dos ensaios.

\section{REFERÊNCIAS}

1 Hart LD. Alumina chemicals: Science and technology handbook. EUA: The American Ceramic Society; 1990.

2 Castro RHR. Estudo da influência de aditivos na transformação de fase gama-alfa da alumina; Tese de Doutorado; São Paulo: Escola Politécnica da Universidade de São Paulo; 2005.

3 Wakao Y, Hibino T. Effects of metallic oxides on $\alpha$-transformation of alumina. Nagoya Kogyo Gijutu Shikensho Hokoku. 1962; 588-595.

4 Machida M, Eguchi K, Arai H. Preparation and characterization of large surface area $\mathrm{BaO} .6 \mathrm{Al}_{2} \mathrm{O}_{3}$. Bull. Chem. Soc. Jpn. 1988: 3659-3665.

5 Okada K, Hattori A, Taniguchi T. Effect of Divalent Cation Additives on the $\mathrm{y}-\mathrm{Al}_{2} \mathrm{O}_{3}$-to- $\alpha-$ $\mathrm{Al}_{2} \mathrm{O}_{3}$ Phase Transition. J.Amer. Cer. Soc. 2000; 83(4): 928-932

6 Yoldas BE. Thermal stabilization of an active alumina and effects of dopants on the Surface Area. J.Mater. Sci. 1976; 465-470.

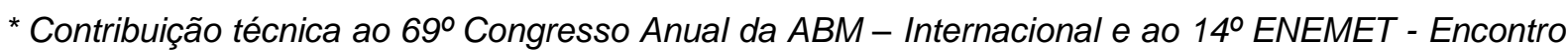
Nacional de Estudantes de Engenharia Metalúrgica, de Materiais e de Minas, 21 a 25 de julho de 2014, São Paulo, SP, Brasil.
} 
$7 \mathrm{Xu} \mathrm{Y}, \mathrm{He} \mathrm{Y}$, Yuan X. Preparation of nanocrystalline $\mathrm{Sr}_{3} \mathrm{Al}_{2} \mathrm{O}_{6}$ powders via citric acid precursor. Powder Technology. 2007; 99-102.

8 Chen X, Liu Y, Niu G, Yang Z, Bian M, He A. High temperature thermal stabilization of alumina modified by lanthanum species. Applied Catalysis A: General 205. 2001; 159172.

9 Vishista K, Gnanam Fd. Effect of strontia on the densification and mechanical properties of sol-gel alumina. Ceram. Intern.2006; 32: 917-922.

10 Pereira Gj, Ortega Fs. Synthesis and Characterization of SrO-Supported $\mathrm{Al}_{2} \mathrm{O}_{3}$ Applied as Heterogeneous Catalyst. Materials Science Forum (Online). 2012; 727-728: 11081112.

11 Rahaman M.N. Ceramic processing and sintering. Nova York: 2nd Edition.Taylor \& Francis; 2005

12 Patnaik P, Handbook of Inorganic Chemicals; 2002

13 Chiang Ym, Birnie D, Kingery Wd. Physical Ceramics - Principles for Ceramic Science and Engineering, John Wiley \& Sons Inc.; 1997.

* Contribuição técnica ao 69ำ Congresso Anual da ABM - Internacional e ao 14ํㅡㄹ ENEMET - Encontro Nacional de Estudantes de Engenharia Metalúrgica, de Materiais e de Minas, 21 a 25 de julho de 2014, São Paulo, SP, Brasil. 